The results obtained are reported here with an emphasis laid on factors liable to interfere with the accuracy of the diagnosis. Moreover, the effect of echotomography on the main parameters of reproduction and culling is analysed in some herds.

Pregnancy was diagnosed with an overall accuracy of $96.7 \%$ in 1605 scans performed in 48 herds. Between 18 and $21 \mathrm{~d}$, the percentage of errors in positive diagnoses (DG+) reached $7 \%$, but it was higher in negative diagnoses $(30 \%)$. Beyond $22 \mathrm{~d}$ post-insemination, the error was samll : $3 \%$ or less.

The accuracy of diagnoses performed by experienced operators (more than 200 scans) was always higher : 97.5 versus $94.9 \%$ in inexperienced operators (less than 200 scans). Most errors were made by the latter between 18 and 25 days. A period of training and of adaptation to the scanner is therefore very important. It is more or less long depending on the skill of the operator. Likewise, litter order and genotype have a significant effect on the accuracy of diagnosis. In order to determine the effect of this technique on herd management, we have analysed matings and their results (return to oestrus, farrowing, culling and its cause) in 4 herds during the 12 months preceding the application of ultrasound scanning (period I) and during one year of regular application of this technique to presumably pregnant sows (period II). It was concluded that ultrasound scanning offers a practical means of controlling returns to oestrus in barren sows and of reducing the unproductive periods. The mating-culling interval was reduced from 96 to 46 days on an average for period II.

\title{
Use of ultrasound echography on-the-farm to detect abnormalities of the urogenital tract of sows
}

\author{
F. MADEC (1), Françoise MARTINAT-BOTTE ${ }^{(2)}$, Y. FORGERIT ${ }^{(3)}$, \\ M. LE DENMAT ${ }^{(4)}$, J.C. VAUDELET ${ }^{(4)}$
}

(1) Ministère de l'Agriculture, Direction de la Qualité, Station de Pathologie Porcine, B.P. 9, 22400 Ploufragan. (2) I.T.P.-M.N.E., 149, rue de Bercy, 75595 Paris Cedex 12.

(3) INRA-S.E.I.A., 86480 Rouillé.

(4) I.T.P.-La Motte au Vicomte, 35650 Le Rheu.

Sterile or subfertile sows may stay on the farm for several weeks leading to economic losses. As previous data from the inspection of urogenital tracts of sows at the slaughterhouse had sown a noticeable prevalence of lesions, it was decided to use ultrasound scanning as mean of diagnosing earlier some physiopathological lesions of the urogenital tract of sows.

A first study was conducted a the slaughterhouse. A total of 106 sows were scanned with a BMode scanner (TOSHIBA, SAL $32 \mathrm{~B}$ ) just before slaughter. Images were recorded with a video tape recorder. After slaughter, the urogenital tract was removed and observed at the laboratory. Thereafter, the recorded images were compared to macroscopic observations. A second study involving 162 sows was made in two herds severely affected with reproductive disorders (farrowing rate of 50 or $60 \%$ ).

Ultrasound echography allowed to detect ovaries exhibiting cystic follicles (attached black spots, $15-70 \mathrm{~mm}$ diameter separated by a thin wall) or hemorrhageic corpora lutea (blood clots appearing as attached or not black spots of $12-20 \mathrm{~mm}$ diameter surrounded by a thicker wall). The ovaries could be easily located especially during the follicular phase $(70 \%$ of such ovaries were detected). During the luteal phase, the percentage was lower (51\%). Bladder abnormalities (stones, purulent cystitis) or abcesses were also detected. Uterus abnormalities such as pyometritis were seldom observed during post-mortem examinations and scans were difficult to interprete. 